\title{
The impact of chorionicity on maternal and fetal outcomes
}

\author{
Leonor Bivar $^{1 *}$, Maria Casteleiro ${ }^{1}$, Rita $\operatorname{Vasconcelos}^{1}$, Ana Borges ${ }^{1}$, Cátia Abreu ${ }^{1}$, \\ Isabel Reis ${ }^{1}$, Ricardo Sousa-Santos ${ }^{2,3}$
}

\begin{abstract}
${ }^{1}$ Department of Gynaecology and Obstetrics, Hospital de Braga, Braga, Portugal
${ }^{2}$ Department of Gynaecology and Obstetrics, Hospital Senhora da Oliveira, Guimarães, Portugal

${ }^{3}$ Center for Health Technology and Services Research - CINTESIS, Porto, Portugal
\end{abstract}

Received: 17 November 2020

Accepted: 16 December 2020

\section{*Correspondence:}

Dr. Leonor Bivar,

E-mail: leonorbivar@gmail.com

Copyright: (C) the author(s), publisher and licensee Medip Academy. This is an open-access article distributed under the terms of the Creative Commons Attribution Non-Commercial License, which permits unrestricted non-commercial use, distribution, and reproduction in any medium, provided the original work is properly cited.

\begin{abstract}
Background: Women carrying twin pregnancies receive extensive antenatal counselling on fetal risks, but less is known about whether the presence of two placentas confers dissimilar maternal risks. We pretend to determine the impact of chorionicity on the maternal and fetal outcome, evaluating the possibility of finding the association between complications and the presence of two placental masses.

Methods: We conducted a retrospective observational cohort study of 550 twin pregnancies monitored at a level-3 hospital, between January 2004 and December 2018.

Results: Of the 550 pregnancies, 419 (76.2\%) were bichorionic and 131 (23.8\%) were monochorionic. Caesarean delivery was more frequent in monochorionic group $(70.2 \%$ vs. $61.8 \%, \mathrm{p}=0.05)$. There were no statistically significant differences in the proportion of adverse maternal outcomes between bichorionic and monochorionic pregnancies, despite a trend towards higher proportions in bichorionic group. Regarding fetal outcomes, monochorionic twins were delivered earlier (mean gestational age of $34^{+4}$ weeks vs. $35^{+1}$ weeks, $\mathrm{p}=0.04$ ) and the proportion of preterm delivery cases between $32^{+0}$ and $36^{+6}$ weeks was higher in monochorionic pregnancies $(72.5 \%$ vs. $54.9 \%, \mathrm{p}=0.002)$. Stillbirth of one or both twins was more frequent in monochorionic group $(3.1 \%$ vs. $0.5 \%$, $\mathrm{p}=0.03)$.

Conclusions: The presence of two placental masses does not seems to confer an increase in maternal risks, despite a trend towards higher proportions of adverse outcomes in bichorionic pregnancies. However, monochorionicity is associated with an increase in fetal risks, particularly prematurity. Counselling and monitoring of bichorionic or monochorionic pregnancies may be identical with respect to maternal risks, but chorionicity should be considered when evaluating fetal risks.
\end{abstract}

Keywords: Chorionicity, Fetal outcome, Maternal outcome, Twin pregnancy

\section{INTRODUCTION}

Over the last 20 years, the number of multifetal pregnancies, including twin pregnancies, has increased significantly, representing approximately $3-4 \%$ of all pregnancies. ${ }^{1,2}$ The increasing incidence is mainly due to delayed childbearing (associated with higher multiple birth rate) as well as to the use of assisted reproductive techniques (ART) ${ }^{3-5}$ Dizygotic twins are more common than monozygotic twins, approximately 70 and 30 percent of twins, respectively (in the absence of the use of ART). ${ }^{6}$

While the prevalence of monozygotic twin pregnancies is relatively stable worldwide at 3 to 5 per 1000 births, dizygotic twin pregnancies are influenced by different factors including heredity, ethnicity and maternal age. .,4,7 $^{-4}$ 
A twin pregnancy involves careful monitoring because it is associated with higher rates of almost every potential complication of pregnancy compared to single pregnancies. ${ }^{8}$ Evidence on the increased perinatal risks of monochorionic (MC) compared with bichorionic (BC) twin pregnancies is well established. In addition to twintwin transfusion syndrome (TTTS), monochorionicity imparts greater risk of perinatal mortality, stillbirth, intrauterine death after 32 weeks, twin growth discordance (TGD), neonatal intensive care unit admission, and preterm birth (PTB) compared to BC twins. ${ }^{9-12}$

As a result, women carrying twin pregnancies receive extensive antenatal counselling on fetal risks, but less is known about whether the presence of one versus two placentas confers dissimilar maternal risks. In fact, the provided prenatal care is identical whether it is a $\mathrm{BC}$ or $\mathrm{MC}$ twin pregnancy, apart from complications unique to the latter.

The aim of this study was to determine the impact of chorionicity on maternal and fetal outcomes. We hypothesized that perinatal risks are higher in $\mathrm{MC}$ pregnancies while maternal risks are higher in women with BC pregnancies due to the presence of two placental masses.

\section{METHODS}

We conducted a retrospective data analysis based on clinical records of 550 twin pregnancies monitored at a level-3 hospital, between January 2004 and December 2018, after approval from the Institutional Review Board.

Pregnancies were classified as diamniotic MC or BC according to ultrasonographic criteria and to postpartum histological assessment of the placenta. Major fetal abnormalities, monoamniotic pregnancies and complications unique to MC, such as TTTS, twin anemiapolycythemia sequence (TAPS), and twin reversed arterial perfusion (TRAP), were excluded from the study.
Clinical complications measured were: fetal growth restriction (FGR), pre-eclampsia, HELLP syndrome, cholestasis, and gestational diabetes diagnosis were established in an antenatal examination according to the criteria used by national and international recommendations; TGD diagnosis which was diagnosed when a $20 \%$ or higher weight difference between twins was detected; TTTS, TAPS and TRAP were diagnosed according to ultrasonographic criteria; PTB was defined as labor before the $37^{\text {th }}$ week of gestational age; fetal deaths as one occurred after 24 weeks of gestation., ${ }^{2,13,9}$

We also collected data on maternal age, conception type (spontaneous or resulting from ART), gestational age (GA) and birth weight (BW) at delivery, and delivery type.

Chi-square and Student's t-test were applied in data assessment, with a p-value of $<0.05$ considered statistically significant, using SPSS version 23.0 software.

\section{RESULTS}

Of the 550 pregnancies monitored at our Department, 419 (76.2\%) were BC and 131 (23.8\%) were MC.

Table 1 shows the baseline characteristics of our study population according to chorionicity. Maternal age differed between BC and MC pregnancies, with a greater proportion of advanced maternal age (mothers older than 35 years old) in the BC group (30.1\% vs. $22.1 \%, \mathrm{p}=0.05)$. Also, body mass index (BMI) was higher in BC group (35.1 kg/m2 vs. $34.6 \mathrm{~kg} / \mathrm{m} 2, \mathrm{p}=0.04)$. Number of gestations, maternal chronic hypertension, and diabetes mellitus did not significantly differ between the two groups (Table 1).

As expected, there was an association between BC pregnancies and conception after ART (19.8\% vs. $4.6 \%$, $\mathrm{p}<0.001)$ and between MC pregnancies and spontaneous conception $(94.7 \%$ vs. $77.3 \%$, p<0.001) (Figure 1).

Table 1: Maternal characteristics by chorionicity.

\begin{tabular}{|c|c|c|c|}
\hline Characteristic & $\begin{array}{l}\text { Bichorionic } \\
(n=419)\end{array}$ & $\begin{array}{l}\text { Monochorionic } \\
(n=131)\end{array}$ & P value \\
\hline Maternal age, mean yo (SD) & $31.8(4.8)$ & $30.7(4.7)$ & 0.02 \\
\hline $\begin{array}{l}\text { Advanced maternal age }>35 \text { yo, } \\
\text { n }(\%)\end{array}$ & $126(30.1)$ & $29(22.1)$ & 0.05 \\
\hline$<18$ yo, n $(\%)$ & $3(0.7)$ & $1(0.8)$ & 0.66 \\
\hline BMI $\left(\mathrm{kg} / \mathrm{m}^{2}\right)$, mean (SD) & $35.1(2.5)$ & $34.6(2.4)$ & 0.04 \\
\hline Number of gestations, median & 1 & 2 & 0.72 \\
\hline Chronic hypertension, n (\%) & $10(2.4)$ & $7(5.3)$ & 0.08 \\
\hline Diabetes mellitus, n (\%) & $3(0.7)$ & 0 & 0.44 \\
\hline
\end{tabular}

Student's t-test were applied in data assessment, with a p-value of $<0.05$ considered statistically significant, BMI, body mass index, yo, years old 
Table 2: Maternal outcome by chorionicity.

\begin{tabular}{|llll|}
\hline Maternal Outcome, $\mathbf{N}(\%)$ & $\begin{array}{l}\text { Bichorionic } \\
(\mathbf{n = 4 1 9 )}\end{array}$ & $\begin{array}{l}\text { Monochorionic } \\
(\mathbf{n = 1 3 1})\end{array}$ & P value \\
\hline HELLP/Pre-eclampsia & $29(6.9)$ & $6(4.6)$ & 0.23 \\
\hline Gestational hypertension & $9(2.1)$ & $2(1.5)$ & 0.49 \\
\hline Cholestasis & $8(1.9)$ & $2(1.5)$ & 0.56 \\
\hline Gestational diabetes & $49(11.7)$ & $18(13.7)$ & 0.31 \\
\hline PPROM & $66(15.8)$ & $14(10.7)$ & 0.10 \\
\hline Preterm labor & $78(18.6)$ & $20(15.3)$ & 0.23 \\
\hline Placental abruption & $14(3.2)$ & $2(1.5)$ & 0.22 \\
\hline Caesarean delivery & $259(61.8)$ & $92(70.2)$ & 0.05 \\
\hline
\end{tabular}

Chi-square were applied in data assessment, with a p-value of $<0.05$ considered statistically significant, PPROM, preterm prelabor rupture of membranes.

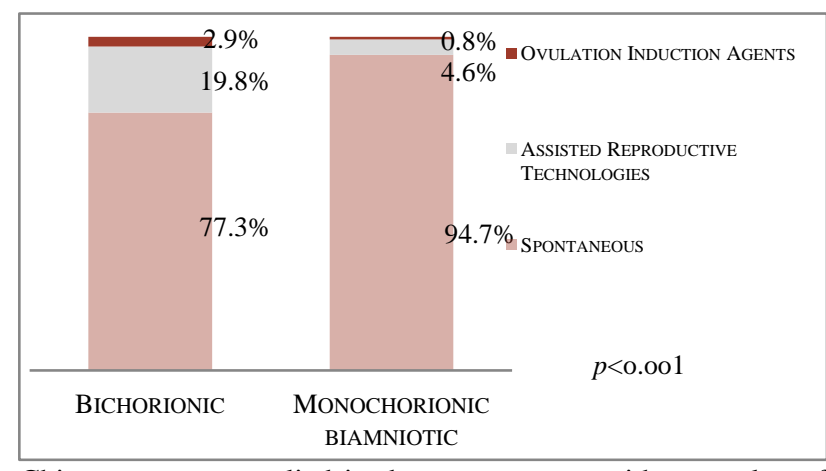

Chi-square were applied in data assessment, with a p-value of $<0.05$ considered statistically significant

Figure 1: Association between type of conception and chorionicity.

Regarding maternal outcomes (Table 2), caesarean delivery was more frequent in MC group (70.2\% vs. $61.8 \%, \mathrm{p}=0.05)$. The incidence of HELLP syndrome or pre-eclampsia was not significantly different in $\mathrm{BC}$ versus MC pregnancies $(6.9 \%$ vs. $4.6 \%, \mathrm{p}=0.23)$, despite a trend towards higher proportion of the adverse outcome in the BC group (Table 2). We did a subgroup analysis in women with advanced age, chronic hypertension or gestational hypertension with no change in the results for HELLP syndrome or pre-eclampsia (Table 3).
There were no statistically significant differences in the proportion of cases of gestational hypertension, cholestasis, gestational diabetes, preterm prelabor rupture of membranes (PPROM), preterm labor or placental abruption between $\mathrm{BC}$ and $\mathrm{MC}$ pregnancies (Table 2). There was, however, a trend towards higher proportions of adverse maternal outcomes in BC group, except for gestational diabetes (11.7 vs. $13.7 \%, \mathrm{p}=0.31)$. A higher incidence of HELLP/Pre-eclampsia $(6.9 \%$ vs. $4.6 \%$, $\mathrm{p}=0.23)$, gestational hypertension $(2.1 \%$ vs. $1.5 \%$, $\mathrm{p}=0.49)$, PPROM (15.8\% vs. $10.7 \%, \mathrm{p}=0.10)$, preterm labor $(18.6 \%$ vs. $15.3 \%, \mathrm{p}=0.23)$ and placental abruption (3.2\% vs. $1.5 \%, \mathrm{p}=0.22$ ) was found in $\mathrm{BC}$ group (Table 2).

Regarding fetal outcomes (Table 4), MC twins were delivered earlier, at a mean gestational age of $34+4$ weeks versus $35+1$ weeks for $B C$ twins $(p=0.04)$. The proportion of preterm delivery cases between $32+0$ and $36+6$ weeks was higher in MC pregnancies $(72.5 \%$ vs. $54.9 \%, \mathrm{p}=0.002)$. Also, stillbirth of one or both twins was more frequent in $\mathrm{MC}$ group $(3.1 \%$ vs. $0.5 \%, \mathrm{p}=0.03)$. Despite not statistically significant, the proportion of FGR or TGD was higher in MC group (26.7\% vs. $23.6 \%$, $\mathrm{p}=0.27$ ) (Table 4).

Table 3: Subgroup analysis of HELLP syndrome or pre-eclampsia by advanced maternal age, chronic hypertension or gestational hypertension.

\begin{tabular}{|llll|}
\hline Maternal Outcome, $\mathbf{N}(\%)$ & $\begin{array}{l}\text { Bichorionic } \\
\text { Advanced maternal age }>35\end{array}$ & $\begin{array}{l}\text { Monochorionic } \\
\text { Ao } \\
(\mathrm{n}=126)\end{array}$ & $\begin{array}{l}\text { Advanced maternal age }>35 \text { yo } \\
(\mathrm{n}=29)\end{array}$ \\
\hline HELLP/Pre-eclampsia & $12(9.5)$ & $1(3.4)$ & 0.26 \\
\hline & $\begin{array}{l}\text { Chronic hypertension } \\
(\mathrm{n}=10)\end{array}$ & $\begin{array}{l}\text { Chronic hypertension } \\
(\mathrm{n}=7)\end{array}$ & 0.64 \\
\hline HELLP/Pre-eclampsia & $2(20.0)$ & $1(14.3)$ & 0.27 \\
\hline
\end{tabular}

Chi-square were applied in data assessment, with a p-value of $<0.05$ considered statistically significant 
Table 4: Fetal outcome by chorionicity.

\begin{tabular}{|c|c|c|c|c|}
\hline \multicolumn{2}{|c|}{ Fetal Outcome, N (\%) } & $\begin{array}{l}\text { Bichorionic } \\
(n=419)\end{array}$ & $\begin{array}{l}\text { Monochorionic } \\
(\mathbf{n}=\mathbf{1 3 1})\end{array}$ & P value \\
\hline \multicolumn{2}{|l|}{ FGR/TGD } & $99(23.6)$ & $35(26.7)$ & 0.27 \\
\hline \multicolumn{2}{|c|}{ Stillbirth of one or both twins } & $2(0.5)$ & $4(3.1)$ & 0.03 \\
\hline \multicolumn{2}{|c|}{ GA at delivery, mean (weeks) } & $35^{+1}$ & $34^{+4}$ & 0.04 \\
\hline \multirow{4}{*}{$\begin{array}{l}\text { GA at delivery } \\
\text { (weeks) }\end{array}$} & $24^{+0}-27^{+6}$ & $5(1.2)$ & $2(1.5)$ & \multirow{4}{*}{0.002} \\
\hline & $28^{+0}-31^{+6}$ & $37(8.8)$ & $10(7.6)$ & \\
\hline & $32^{+0}-36^{+6}$ & $230(54.9)$ & $95(72,5)$ & \\
\hline & $>37^{+0}$ & $147(35.1)$ & $24(18.3)$ & \\
\hline
\end{tabular}

Chi-square were applied in data assessment, with a p-value of $<0.05$ considered statistically significant, FGR, fetal growth restriction, TGD, twin growth discordance

\section{DISCUSSION}

Twin pregnancy has increased significantly over the last years. ${ }^{1,2}$ The use of ART has greatly contributed to this reality. ${ }^{3-5}$ Apart from ART, our findings also suggest delayed childbearing a determinant factor for chorionicity, as maternal age was slightly higher for BC pregnancies than the observed for MC.

We reported that $\mathrm{BC}$ pregnancies were more frequently associated with ART. Recent studies have suggested that ART are associated with a higher rate of monozygotic twins. However, the magnitude of the association is smaller than previous suggested and the rate more clinically relevant when focusing on the ICSI group. ${ }^{14}$

There is sufficient evidence that twin pregnancy involves several risks for mother. Hypertensive disorders are increased, but data are conflicting whether the risk of gestational diabetes is also higher. ${ }^{15-17}$ However, whether chorionicity has an effect on the risks in pregnant women is still unknown, and studies have reported various results. ${ }^{18,19}$ In line with what has been described, we found that the incidence of hypertensive disorders were higher in BC pregnancies, despite not statistically significant, and that there was a trend towards higher proportion of gestational diabetes in MC pregnancies. We conducted a subgroup analysis in women with advanced age, chronic hypertension or gestational hypertension with no change in the results for HELLP syndrome or pre-eclampsia. However, we cannot draw conclusions since the limited number of cases reported.

Still concerning maternal outcome, we reported that caesarean delivery was more frequent in MC pregnancies, as described by previous studies. ${ }^{2}$ This may be in part explained by a lower mean gestational age at birth and a higher proportion of preterm delivery cases between $32+0$ and $36+6$ weeks in MC pregnancies.

Regarding fetal outcomes, prematurity is a major concern. Some investigators have stated that the worse outcome of monochorionic pregnancies can be ascribed to preterm delivery. ${ }^{12,20}$ We found support for this hypothesis in the finding of significantly more preterm deliveries in $\mathrm{MC}$ than $\mathrm{BC}$ twins.

Several limitations of this study, besides its respective nature, should be considered. One is the small number of outcomes that prevents any firm conclusion, though a larger twin cohort was analysed in this study compared to previous literature. This may be consequence of the relatively low rate of each complication in single and multiples pregnancies.

Another limitation is that our findings may be confounded by the heterogeneity of infertility treated by ART. For instance, recent studies have investigated the possibility of adverse outcomes among ART conceived twin pregnancies compared to spontaneously conceived twin pregnancies and whether these outcomes are further affected by chorionicity. ${ }^{14,21}$ However, it may be an arduous task to control for each type of infertility in a single center study. Again, a well-controlled multicenter study is needed to study the impact of chorionicity on clinical outcomes.

\section{CONCLUSION}

In conclusion, the presence of two placental masses does not seems to confer an increase in maternal risks, since no statistically significant differences were found in the majority of maternal outcomes between $\mathrm{BC}$ and $\mathrm{MC}$ twin pregnancies, despite a trend towards higher proportions of adverse outcomes in bichorionic pregnancies. In fact, the exception refers to caesarean delivery that was more frequent in MC pregnancies. However, monochorionicity is associated with an increase in fetal risks, particularly regarding prematurity.

Thus, it is suggested that counselling and monitoring of a bichorionic or monochorionic pregnancy may be identical with respect to maternal risks, but chorionicity should be considered when evaluating fetal risks.

\section{ACKNOWLEDGMENTS}

The authors wish to acknowledge the Department of Obstetrics at Hospital de Braga for their contribution in antenatal monitoring, and especially want to thank 
Belandina Gil, MD, for her dedication to surveillance of twin pregnancies.

Funding: No funding sources Conflict of interest: None declared

Ethical approval: The study was approved by the Ethics Committee Institutional Review Board of Hospital de Braga

\section{REFERENCES}

1. Rodrigues CT, Branco MR, Ferreira ID, Nordeste A, Fonseca M, Taborda A, et al. Multiple gestation epidemiology - 15 years survey. Acta Med Port. 2005;18:107-11.

2. Manso P, Vaz A, Taborda A, Silva IS. Chorionicity and perinatal complications in twin pregnancy: a 10 years case series. Acta Med Port. 2011;24:695-8.

3. Kupka MS, D'Hooghe T, Ferraretti AP, de MJ, Erb $\mathrm{K}$, Castilla JA, et al. Assisted reproductive technology in Europe, 2011: results generated from European Registers by ESHRE. Hum Reprod. 2016;31(2):233e48.

4. Endres L, Wilkins I. Epidemiology and biology of multiple gestations. Clin Perinatol. 2005;32:301-14.

5. Rodrigues CT, Branco MR, Ferreira ID, Nordeste A, Fonseca M, Taborda A, et al. Multiple gestation epidemiology - 15 years survey. Acta Med Port. 2005;18:107-11.

6. Dubé J, Dodds L, Armson BA. Does chorionicity or zygosity predict adverse perinatal outcomes in twins? Am J Obstet Gynecol. 2002;186:579.

7. Parazzini F, Cipriani S, Bianchi S, Bulfoni C, Bortolus R, Somigliana E. Risk of monozygotic twins after assisted reproduction: a population-based approach. Twin Res Hum Genet. 2016;19:72-6.

8. Chauhan SP, Scardo JA, Hayes E, Abuhamad AZ, Berghella V. Twins: prevalence, problems, and preterm births. Am J Obstet Gynecol. 2010;203:305.

9. Sebire NJ, Snijders RJ, Hughes K, Sepulveda W, Nicolaides KH. The hidden mortality of monochorionic twin pregnancies. $\mathrm{Br} \quad \mathrm{J}$ Obstet Gynaecol. 1997;104:1203.

10. Adegbite AL, Castille S, Ward S, Bajoria R. Neuromorbidity in preterm twins in relation to chorionicity and discordant birth weight. Am J Obstet Gynecol. 2004;190:156.

11. Leduc L, Takser L, Rinfret D. Persistence of adverse obstetric and neonatal outcomes in monochorionic twins after exclusion of disorders unique to monochorionic placentation. Am J Obstet Gynecol. 2005;193:1670.

12. Hack KE, Derks JB, Elias SG, Franx A, Roos EJ, Voerman SK, et al. Increased perinatal mortality and morbidity in monochorionic versus dichorionic twin pregnancies: clinical implications of a large Dutch cohort study. BJOG. 2008;115:58.

13. Sperling L, Tabor A. Twin pregnancy: the role of ultrasound in management. Acta Obstet Gynecol Scand. 2001;80:287-99.

14. Fabio Parazzini, Sonia Cipriani, Stefano Bianchi, Camilla Bulfoni, Renata Bortolus, Edgardo Somigliana. Risk of Monozygotic Twins After Assisted Reproduction: A Population-Based Approach. Twin Research and Human Genetics. 2006;19:72-76.

15. Sibai BM, Hauth J, Caritis S, Lindheimer MD, MacPherson C, Klebanoff $\mathrm{M}$, et al. Hypertensive disorders in twin versus singleton gestations. Am $\mathrm{J}$ Obstet Gynecol. 2000;182:938-942.

16. Buhling KJ, Henrich W, Starr E, Lubke M, Bertram $\mathrm{S}$, Siebert G, et al. Risk for gestational diabetes and hypertension for women with twin pregnancy compared to singleton pregnancy. Arch Gynecol Obstet. 2003;269:33-36.

17. Rauh-Hain JA, Rana S, Tamez H, Wang A, Cohen B, Cohen A, et al. Risk for developing gestational diabetes in women with twin pregnancies. J Matern Fetal Neonatal Med. 2009;22:293-299.

18. A. Victoria, G. Mora, F. Arias. Perinatal outcome, placental pathology, and severity of discordance in monochorionic and dichorionic twins. Obstet Gynecol. 2001;97:310-15.

19. Feng B, Zhai J, Cai Y. Effect of twin pregnancy chorionic properties on maternal and fetal outcomes. Taiwan J Obstet Gynecol. 2018;57(3):351-4.

20. Cunningham FG, MacDonald PC, Gant NF, Leveno KJ, Gilstrap LC III, Hankins GDV, et al. Williams obstetrics. 20th ed. Stanford, Connecticut: Appleton \& Lange. 1997:880.

21. Qin J, Wang H, Sheng X, Liang D, Tan H, Xia J. Pregnancy-related complications and adverse pregnancy outcomes in multiple pregnancies resulting from assisted reproductive technology: a meta-analysis of cohort studies. Fertil Steril. 2015;103:1492-508.

Cite this article as: Bivar L, Casteleiro M, Vasconcelos R, Borges A, Abreu C, ReisI, Pandey A, et al. The impact of chorionicity on maternal and fetal outcomes. Int J Reprod Contracept Obstet Gynecol 2021;10:39-43. 